\title{
REPENSAR A CIDADE: INTERVENÇÃO EFÊMERA COMO INSTRUMENTO DE DISCUSSÃO DE ESPAÇOS RESIDUAIS NO CENTRO DA CIDADE DE PRESIDENTE PRUDENTE - SP
}

\author{
Julia Salomão dos Santos Favareto, Fabrícia Dias da Cunha de Moraes Fernandes \\ Universidade do Oeste Paulista - UNOESTE, Presidente Prudente, SP. E-mail: ju.salo79@gmail.com
}

\begin{abstract}
RESUMO
A cidade de Presidente Prudente, munícipio que se iniciou com duas áreas desenvolvidas a partir da Estrada de Ferro Sorocabana, passou por uma acelerada expansão urbana sem planejamento, a qual depois se configurou em um espaço urbano com necessidade por circulação e espaços públicos de qualidade, acarretando no surgimento de diversos espaços residuais. Alguns exemplos de resíduos urbanos da cidade, os quais possuem forte identidade local são o Viaduto Comendador Tannel Abbud e a linha férrea, inserida em seu baixio. O Viaduto, após sua construção (1970), na área central da cidade, ocasionou na descaracterização do entorno onde foi implantado e diminuiu o uso do local. A área inferior do viaduto, tratada pela literatura acadêmica como espaço residual, compreende-se por ser ocioso e desvalorizado, com conflitos de uso entre comércio informal e moradores de rua. Para tanto, o objetivo da trabalho é investigar o histórico e dinâmicas desse espaço, trazendo como instrumento para mitigar os problemas destas áreas a intervenção de caráter efêmero, a fim de gerar amabilidade urbana. Desta forma, fazendo-o espaços de apoio as manifestações locais ao inserir e manter usos no seu baixio, estabelecendo ali um espaço público. Portanto, o trabalho utiliza a metodologia pautada na pesquisa bibliográfica e análise qualitativa, por meio de revisões bibliográficas e documentais, levantamento in loco e interpretação de tais dados. E por fim, o desenvolvimento de propostas de intervenção com diretrizes para a área em estudo.

Palavras-chave: Espaço residual. Espaço público. Intervenção efêmera. Presidente Prudente - SP. Baixio do Viaduto Tannel Abbud.
\end{abstract}

\section{RETHINKING THE CITY: EPHEMERIC INTERVENTION AS AN INSTRUMENT FOR DISCUSSION OF RESIDUAL SPACES IN THE CITY CENTER OF PRESIDENTE PRUDENTE - SP}

\begin{abstract}
The city of Presidente Prudente, a municipality that started with two areas developed from the Sorocabana Railway, underwent an accelerated urban expansion without planning, which later became an urban space in need of circulation and quality public spaces, resulting in the emergence of several residual spaces. Some examples of urban waste in the city, which have a strong local identity are the Viaduto Comendador Tannel Abbud and the railway line, inserted in its shallow. The Viaduct, after its construction (1970), in the central area of the city, caused the de-characterization of the surroundings where it was implanted and decreased the use of the site. The lower area of the viaduct, treated by academic literature as a residual space, is understood to be idle and devalued, with conflicts of use between informal commerce and homeless people. To this end, the objective of the dissertation is to investigate the history and dynamics of this space, bringing ephemeral intervention as an instrument to mitigate the problems of these areas, in order to generate urban kindness. In this way, making it support spaces for local manifestations by inserting and maintaining uses in its shallow, establishing a public space there. Therefore, the work uses the methodology based on bibliographic research and qualitative analysis, through bibliographic and documentary reviews, on-site survey and interpretation of such data. And finally, the development of intervention proposals with guidelines for the area under study.
\end{abstract}

Keywords: Residual space. Public place. Ephemeral intervention. Presidente Prudente - SP. Low of Tannel Abbud Viaduct. 


\section{INTRODUÇÃO}

Durante o século $\mathrm{XX}$, a acelerada urbanização, a evolução da máquina e o incentivo do uso do automóvel, trouxeram problemas na mobilidade nas grandes cidades. Buscando resolver estas demandas de transporte, preferencialmente 0 individual, as cidades implantaram ações desestruturadoras do tecido urbano, como produção de expansões desnecessárias da malha urbana e construções aleatórias e inadequadas. Ocasionando em efeitos devido a esse mau planejamento da infraestrutura viária, como a formação de áreas residuais em pontos de intercepção do tecido urbano, transformando o que era pra ser solução da cidade moderna em obstáculos à qualidade urbana, gerando áreas vazias e descaracterizadas (FURTADO, 2016).

Estes espaços vazios ou resultantes dessas estruturas foram tratados na arquitetura como espaços de abandono ou marginalizados. Identificados por vários autores como espaços residuais ou intersticiais, desse modo caracterizando este espaço urbano não edificado entre terrenos e objetos. E a articulação entre esses espaços podem apresentar ausência ou estar vazios.

Exemplos desses espaços são encontrados na cidade informal (cidades onde não há ativação de alguns espaços públicos permitindo o acesso público, motivando usos informais), gerando uma paisagem incompreensível, que geram incômodo e insegurança por não carregar nenhum tipo de estrutura que potencialize seu espaço (LYNCH, 2010).

Áreas estas, definidas como residuais, as quais antes eram produtivas, viram-se desqualificadas ou abandonadas, agravando o seu estado de degradação física e também, visto que, o mal planejamento de vias rodoviárias (viadutos e pontes) criaram áreas residuais nos pontos de conexão com o tecido urbano tradicional devido as desproporções das vias circulares. Gerando assim fragmentações e cicatrizes nos centros urbanos. Imediatamente estes espaços converteram-se em espaços inseguros onde o seu único atributo para a cidade é de transmitir uma imagem negativa, trazendo assim estes resíduos como problemática do espaço urbano (TIMANA apud SOIÀ MORALES, 2018).
No entanto, o desafio da cidade contemporânea estaria em tentar articular e promover interação entre os espaços públicos e os residuais. Espaços formulados como definidos (espaços públicos) e não definidos (espaços residuais). Ao passo que, a reutilização desses espaços residuais poderia mudar a imagem da cidade (GUATELLI, 2012).

O trabalho procura analisar o baixio de viaduto e seu entorno, espaço considerado como residual da cidade, o considerando a partir de outro caminho: como um espaço de complexidades, que é marca e carrega consigo, diversas histórias e dinâmicas socioespaciais. Revelando desse modo, que este espaço, devido a sua característica construtiva e sua inserção na cidade abriga usos e que tem potencial para se configurar como um espaço público.

Para entender os aspectos reproduzidos pela inserção de estruturas desse porte e compreender os espaços residuais que o circundam é necessário, contextualizar estes resíduos urbanos da cidade e o elemento viaduto a fim de entender de que forma ele foi implantado e porque atualmente ele ainda é entendido como um símbolo de modernidade e progresso.

Como qualquer transformação, a cidade também possui suas modificações de acordo com avanços tecnológicos, esses que influenciam até hoje no modo de se fazer nossas cidades. É notável entender esse processo, o qual o Brasil fez parte, a partir do período da industrialização, com suas influências no planejamento contemporâneo.

Desse modo, a presente pesquisa tem como estudo os espaços residuais no centro da cidade de Presidente Prudente, como objeto de foco o baixio e entorno do viaduto Comendador Tannel Abbud. O qual se localiza no extremo oeste do estado de São Paulo, e foi inserido no núcleo de formação inicial da cidade. O viaduto se encontra no centro da cidade, composto pelos bairros Vila Marcondes e Quadrilátero Central, sendo que o mesmo se acentuou ainda mais a segregação socioespacial que já tinha sido estabelecido pela linha férrea, resíduo urbano que também será tratado, e que se estabelece em seu baixio.

Estes locais foram escolhidos para estudo por conta de serem considerados residuais, e se apresentarem como problemáticas no espaço urbano. Tendo o intuito de gerar contribuições 
para a compreensão de processos de qualificação e de ativação dos espaços públicos e residuais. Esses processos tem potencial para gerar possibilidades efetivas de uso e para tornar seus promotores agentes aptos a exercer papel mais ativo na ordenação do espaço urbano, pois a falta de uso, atratividade e confortabilidade trouxe o esquecimento, degradação e falta de segurança nessa área urbana central de importância histórica para a cidade.

Neste sentido, a presente pesquisa se aprofunda no debate sobre os vazios existentes nos centros urbanos e seus desafios urbanísticos, e em como se tornarem espaços públicos qualificados. Com o enfoque em avaliar as dinâmicas, os conflitos e as relações socioespaciais do local em estudo. Observando a relação existente entre espaço-usuário, identificando as ocupações físicas e sociais. A fim de estabelecer diretrizes projetuais $e$ intervenções efêmeras nesse espaço da cidade, levando em consideração a importância histórica da área, enquadramento urbano e situações sociais e culturais do local. Promovendo um espaço público ativo que se conecte com a cidade, provendo um palco para pedestres e a vida pública.

Assim, com as diretrizes pretende-se apresentar conceitos e ideias de intervenção em espaços residuais no centro da cidade de Presidente Prudente-SP, e salientar como esses espaços têm capacidade de mudar a paisagem urbana, podendo se transformar em espaços públicos de qualidade atendendo a necessidade da população local. Os promovendo também visando a mobilização dos moradores de maneira coletiva e com inclusão de ações culturais.

\section{MÉTODOS}

Com relação ao objetivo proposto por este trabalho, o desenvolvimento deste se dará pela metodologia empregada por meio da pesquisa bibliográfica e documental (com levantamentos de conceitos relacionados ao tema e registros históricos da área em estudo, para identificar os fatos históricos e a relação bairros, viaduto e indivíduos) levantamento in loco (onde serão realizados levantamentos e observações para caracterização da área, a fim de entender a dinâmica do espaço, ou existência de fatos que não constam na literatura), assim como dados e legislação urbanística da área de intervenção. Por fim, será desenvolvido propostas de projeto de intervenção de caráter efêmera e diretrizes projetuais para a área em estudo visando a ativação da mesma.

Os levantamentos de campo foram realizados por meio de visitas ao local e com análise qualitativa, com o intuito de observar as dinâmicas comportamentais quanto a relação espaço-usuário da área em estudo. Estas observações diretas do local também foram complementadas com revisão bibliográfica, pesquisas em bancos de teses e dissertações, artigos científicos embasando o aporte teórico sobre: espaços públicos na contemporaneidade, infraestrutura e expansão urbana e espaço residual urbano.

\section{RESULTADOS}

Os resultados estão apresentados de acordo com o processo histórico de concepção do centro da cidade de Presidente Prudente-SP, da implantação da linha férrea e do Viaduto Comendador Tannel Abbud e de como estas áreas são vistas atualmente dentro do município. Deste modo, há respectivamente, a localização do município; seu desenvolvimento e divisão; a inserção e desuso da linha férrea; a implantação do Viaduto Tannel Abbud; apontando as construções e apropriações que foram adicionadas no perímetro; e, por fim, os recentes processos de revitalização destes espaço pelo Poder Público, destacados através de visitas ao local e dados coletados de reportagens, que buscam identificar como estes impactaram as relações socioespaciais entre espaço-usuário.

\section{ANTECEDENTES URBANOS: COMPREENSÃO E RECONHECIMENTO DA ESPACIALIDADE}

Para discutir as dinâmicas e os conflitos dos espaços públicos e residuais no centro da cidade de Presidente Prudente, é necessário relacionar com o histórico e a estrutura espacial da cidade. Sendo assim, Presidente Prudente-SP (Figura 01), cidade média que se localiza no interior do oeste paulista, pertencente à mesorregião e microrregião de mesmo nome, situa-se a oeste da capital do estado, distando desta cerca de $558 \mathrm{~km}$ (IBGE, 2019). 
Figura 01. Localização do Município de Presidente Prudente - SP.

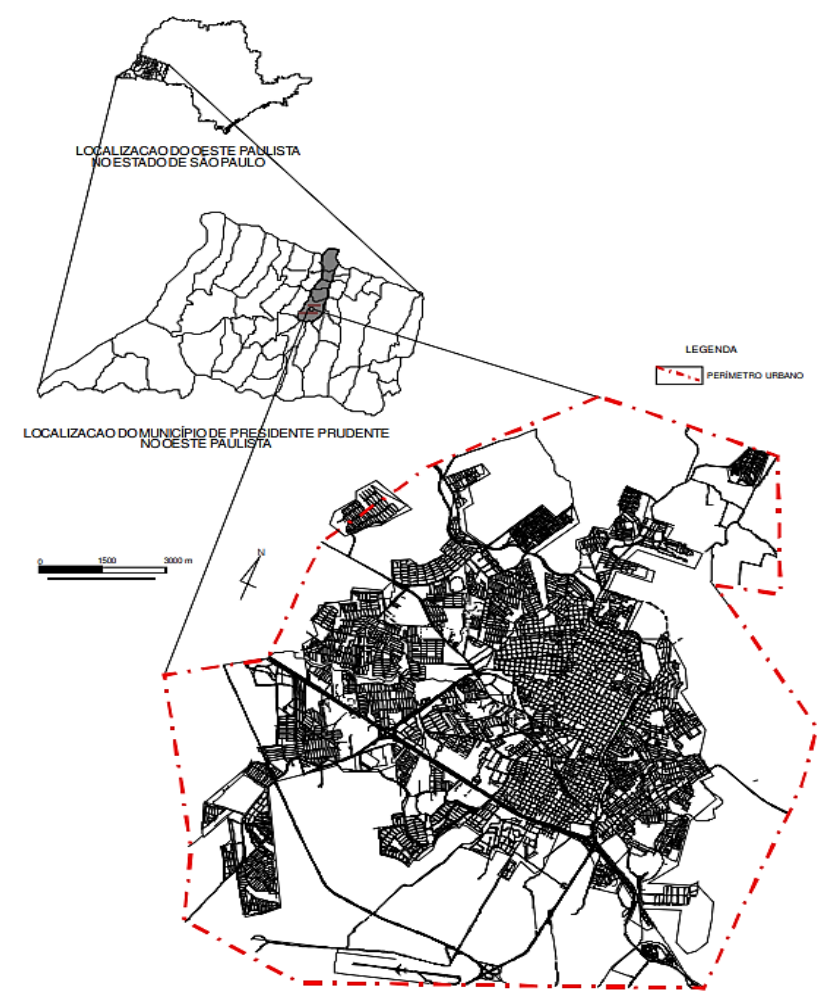

Fonte: IBGE (2019).

O contexto histórico da cidade é marcado pela sua constituição, onde se desenvolveu a partir da implantação da Estrada de Ferro Sorocabana, estabelecida a partir de seu núcleo central, como podemos ver na figura 2. A partir dessa implantação, sua economia passou a ser ligada à cafeicultura e depois passou a ter novas atividades como $O$ cultivo de algodão (PREFEITURA DE PRESIDENTE PRUDENTE, 2017). Por conta destes fatores o centro da cidade é um marco histórico importante para a mesma, que carrega valor de memória para seus moradores.

Figura 2. Núcleo central da cidade

Fonte: Google Earth/Maps (2020). Editado pelo autor. Sem escala

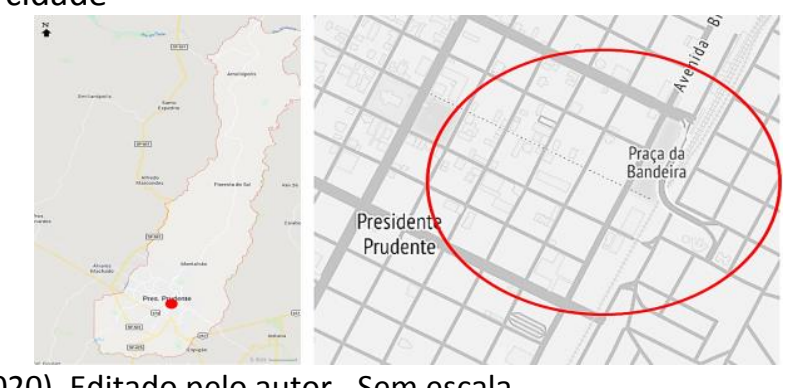

A Estrada de Ferro, desempenhou um importante papel para a cidade. Como entre os anos de 1910 quanto à chegada da população rural e do capital econômico nessa região do Estado de São Paulo, como também foi responsável por dividir a cidade de Presidente Prudente em dois núcleos (ver na figura 3): o lado
Oeste (regularmente plano, idealizado pelo Coronel Goulart) e o lado Leste (idealizado por Coronel José Soares Marcondes) (PREFEITURA DE PRESIDENTE PRUDENTE, 2017). 
Figura 3. Presidente Prudente- SP, em 1923.

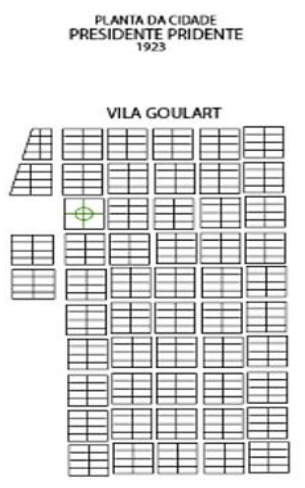

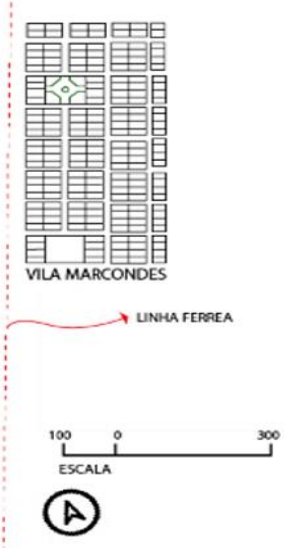

Fonte: Beltrão (1983). Editado pela autora.

Contudo, a ocupação do território de Presidente Prudente foi promovida de dois modos, por dois coronéis (Coronel José Soares Marcondes e Francisco de Paula Goulart), através da implantação de loteamentos como suporte para venda de lotes rurais da gleba. Cada coronel promoveu a ocupação do território de um modo, com isso o processo de formação do núcleo urbano teve características distintas (HIRAO, 2016).

"A ocupação promovida pelo Coronel José Soares Marcondes (na Vila Leste), a partir de 1919, empreendeu características empresariais para época", com a implantação do parcelamento do solo organizado e controlado por seu escritório em São Paulo. Proporcionando infraestrutura para o futuro morador realizar 0 plantio do café (HIRAO, 2016, p.2).

Seu procedimento de ocupação foi baseado em leis, de forma profissional e certificada, o que acarretou em mais custos, fator também aliado a uma área de topografia menos favorável do perímetro. Consequentemente, "a ocupação do seu parcelamento não acompanhou o desenvolvimento e a dinâmica do outro lado da via férrea" (HIRAO, 2016, p.4).

Por outro lado, Coronel Manoel Goulart (idealizador da Vila Oeste), esteve mais preocupado em somente promover a ocupação do território, ou seja, permanecendo no local, o que ajudou a agilizar a burocracia, "facilitando a venda e aquisição dos lotes, inclusive realizando trocas com produção agrícola". O fato do seu loteamento localizar-se em frente à estação e a ter topografia menos acidentada que a outra Vila, favoreceu o processo de expansão urbana e ocupação de seu quadrilátero (HIRAO, 2016, p.3).
Assim, a expansão da cidade ocorreu com maior ênfase a oeste da ferrovia, que era uma "área favorecida pelo relevo mais suave que o existente a leste da estrada de ferro, e que também foi beneficiada pela posição da estação ferroviária, cujas portas estavam voltadas para a Vila Goulart" (BISPO, 2011, p.36).

Depois, com a expansão da cidade, as terras do lado Oeste (atual Vila Goulart), rapidamente foram vendidas e formaram o quadrilátero central da cidade. Já o lado Leste, a atual Vila Marcondes, teve como principal atrativo nos anúncios de comercialização dos seus lotes a fertilidade do solo íngreme. Assim, as duas vilas se uniram formando a paisagem característica de Presidente Prudente (HIRAO, 2016).

No entanto, podemos colocar que o núcleo central da cidade, caracterizado por essas duas ocupações, Vilas Goulart e Vila Marcondes, dão a identidade da cidade. Onde atualmente é popularmente denominado como os dois lados da linha férrea (HIRAO, 2016). Por conta do seu processo de formação com características distintas que resultou em uma divisão na paisagem urbana do centro da cidade.

Ao passo que o centro da cidade de Presidente Prudente é onde se dá a área em estudo, o mesmo é considerado o berço da cidade e o seu principal núcleo de comércio e serviços. Onde se concentram várias atividades, como comerciais, institucionais, culturais e de lazer. Região onde se encontram suas principais praças e equipamentos urbanos no geral, como a igreja matriz, prefeitura da cidade, Procon, escolas, entre outros.

A cidade desde o início desse núcleo central da cidade e sua ocupação (1910-1919), 
com a implantação da linha férrea se viu a necessidade de espaços públicos nesse centro, como espaços de apoio a essa estação ferroviária (local de grande fluxo), para circulação, passagem e trocas sociais. No entanto, no período entre 1920 e 1930 as Vilas Goulart e Marcondes constituem esse centro da cidade com seus espaços livres iniciais, nos quais se configuraram em um esquema de eixo de espaços livres centrais (figura 4), e fizeram também a paisagem da cidade se consolidar de forma diferenciada, dando a Vila Goulart características de centro urbano com as atividades e serviços e a Vila Marcondes área com maior concentração de armazéns e empresas de beneficiamento (HIRAO apud WHITACKER, 1997).

Figura 4.Esquema do eixo de espaços livres centrais

Fonte: Bispo (2011). Editado pela autora.

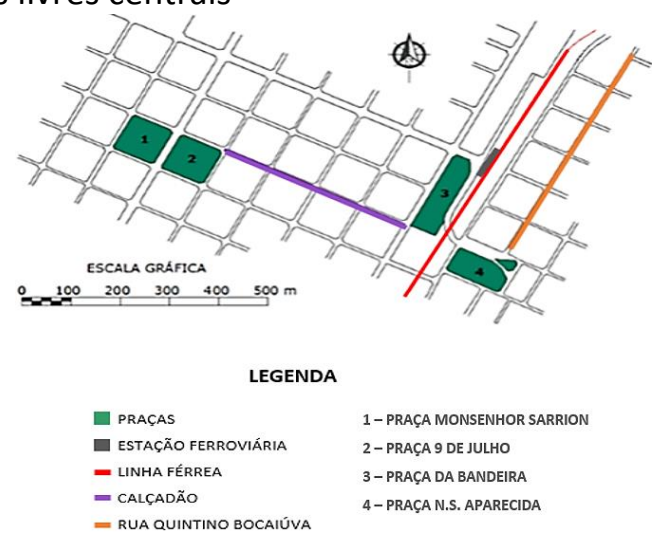

Assim, em meados de 1950, com o contexto da expansão da cidade, ocorreram mudanças significantes, como o declínio do transporte ferroviário e a diminuição no uso da praça da bandeira, consecutivamente também na centralidade que ela representava. Com isso houve a expansão do centro da cidade, e a Praça Nove de Julho e a Praça Monsenhor Sarrion começam a ser o local que representava o encontro de diversas gerações e classes sociais (com seu ápice em 1960). (BISPO, 2011).

Trazendo com isso, uma ligação entre o quadrilátero central (onde se situa as praças Praça Nove de Julho e a Praça Monsenhor Sarrion) e a Vila Marcondes, apresentando futuramente características como o tráfego intenso de ônibus e carros, o conjunto de edificações significantes desse centro, e o rico capital social. Com esse declínio do transporte ferroviário e com a expansão urbana, também ocorreu o crescimento do fluxo de automóveis e aumentaram os problemas de mobilidade urbana na cidade, bem como promoveu o aparecimento de espaços residuais, trazendo a relação e influência da expansão urbana com a mobilidade (AGOSTINHO, 2009).

Em conformidade, junto a expansão urbana surge a necessidade de aumentar a estrutura viária do centro da cidade. Dessa forma, em 1970, foi construído o viaduto Comendador Tannel Abbud (ver figura 5), que buscou melhorar o acesso dos automóveis a Vila Marcondes (HIRAO, 2016).

Figura 05. Construção do viaduto Tannel Abbud na década de 1970.

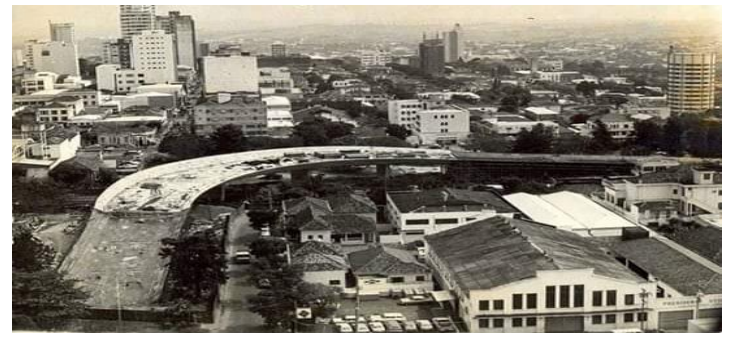

Fonte: Arquivo do Museu e Arquivo Histórico Prefeito Antônio Sandoval Netto. 
O viaduto foi implantado ligando os dois lados da linha férrea, marcando a paisagem urbana. O mesmo cobriu parte da Praça da Bandeira impactando este espaço público da cidade e seu entorno. Com o tempo, a Praça da Bandeira se tornou um local de comércio informal e ocupado por moradores em situação de rua. Contudo, podemos colocar que por conta da acelerada expansão da cidade e seu desenvolvimento urbano a área possui diversos espaços residuais ou que perderam seu uso. Espaços constituintes da área da intervenção proposta. Desse modo, para melhor compreensão, será abordado a delimitação que se configura a área de intervenção.
Sua localização se encontra no centro da cidade de Presidente Prudente - SP, e os espaços que compõem a sua área se caracterizam por espaços que estão dispostos em um eixo imaginário e que se interligam. Como o baixio do Viaduto Tannel Abbud, junto a sua estrutura e entorno imediato, uma parte da linha férrea que se vincula ao viaduto e suas proximidades, como a rua Júlio Tiezzi (em frente à estação ferroviária) e um trecho da rua para pedestres, Rua Tenente Nicolau Maffei (popularmente conhecida como calçadão) (ver figura 6).

Figura 6. Área de intervenção

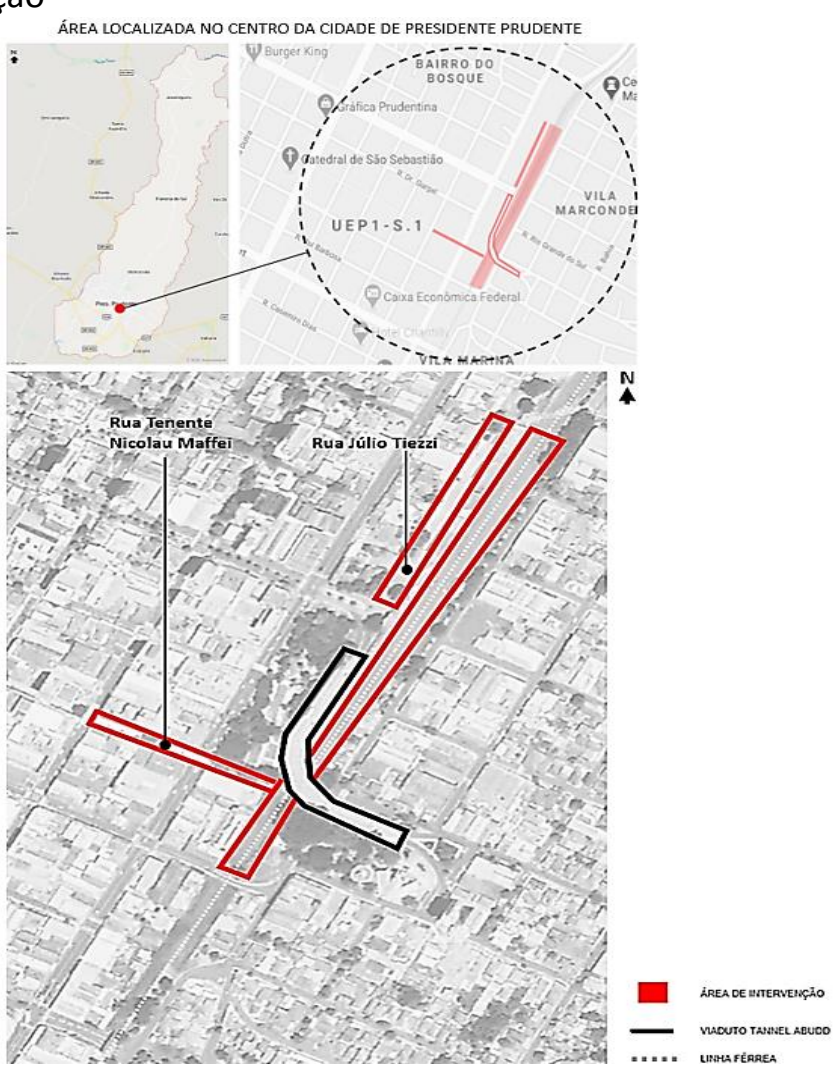

Fonte: Google Earth/Maps (2020). Editado pelo autor. Sem escala

Assim, podemos perceber que a escolha do local de intervenção foi feita cuidadosamente, pensando em áreas residuais que fazem parte do centro urbano da cidade, espaços que são marcas da sua origem, e que possuem um referencial urbano construído, como no seu entorno circundante (viaduto Tannel Abbud, Igreja Nossa Senhora Aparecida, linha férrea e os galpões ferroviários). Dessa forma, trazendo como ponto de partida o viaduto Tannel Abbud, por conta de sua localização, inserido no centro e neste contexto histórico, se comportando como uma cicatriz na malha urbana.

O Viaduto por sua vez se encontra sob a linha férrea, outra cicatriz urbana, também situada como um espaço vazio, ao qual faz integra a área de intervenção. O que torna ambos configuração desse perímetro de estudo. Continuamente, a Rua Júlio Tiezzi (em frente à estação ferroviária) e um trecho da Rua Tenente Nicolau Maffei (conhecido popularmente como calçadão) também foram interligados a esta área 
por serem espaços públicos que se configuram no entorno destes vazios e que os conectam de certa forma (ver na figura 7).

Figura 7. Área de intervenção com os espaços que a constituem
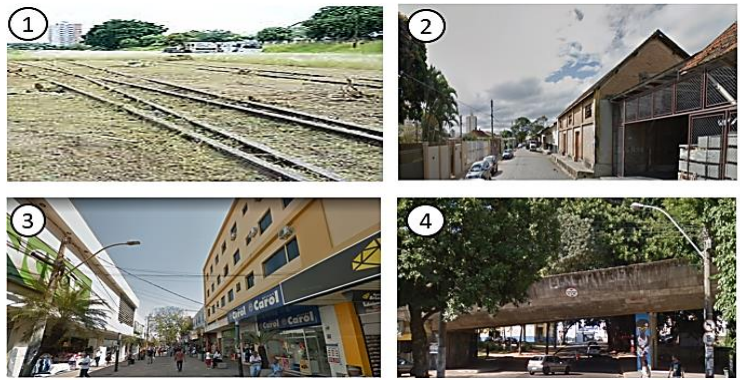

Fonte: Prefeitura Municipal de Presidente Prudente (2020). Editado pela autora.

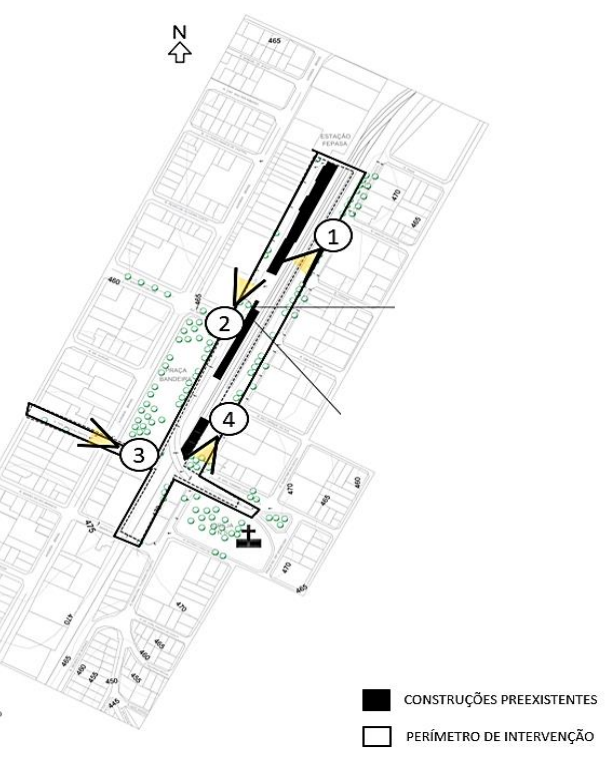

De tal modo, como apontado anteriormente, a área do Viaduto faz parte do perímetro de intervenção, e observamos que uma das modificações advinda da expansão urbana da cidade de Presidente Prudente foi a

Figura 8. Localização do Viaduto Tannel Abbud

Fonte: Google Earth/Maps (2020). Editado pela autora.

A construção do viaduto Comendador Tannel Abbud (1970), se deu a fim de melhorar o acesso dos automóveis a Vila Marcondes, porém em sua constituição não houve preocupação do poder público com o contexto local e as possíveis consequências da implantação da estrutura viária na paisagem urbana. $O$ que acarretou na descaracterização do espaço. Diante disso, Hirao $(2016$, p.7) pondera que:

$$
\text { [...] este objeto elevado }
$$

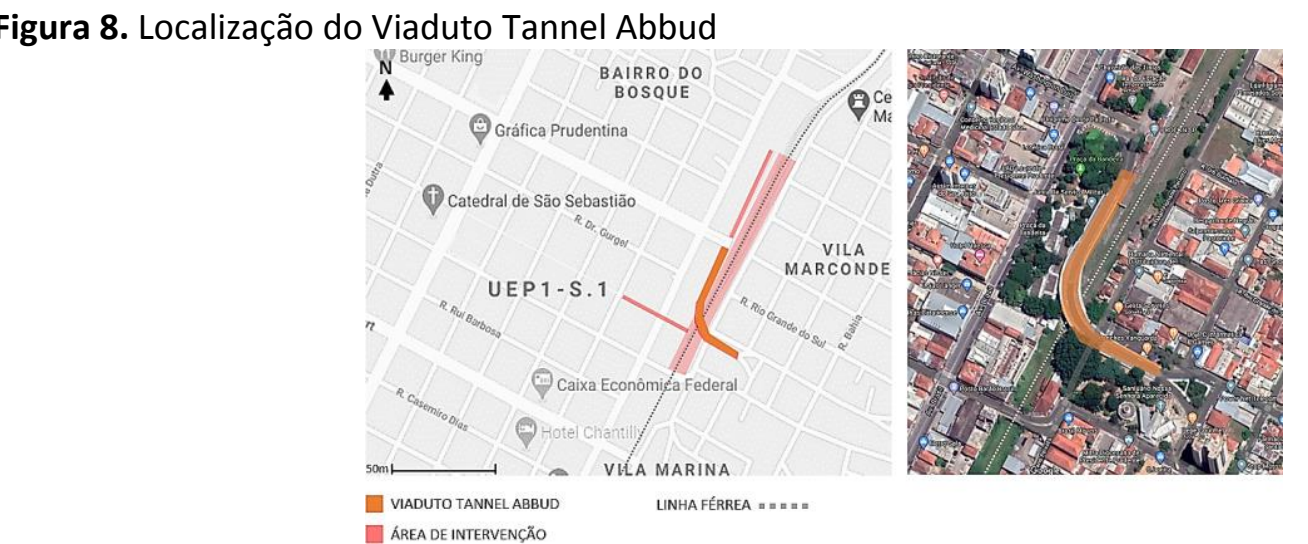

implantação do Viaduto Tannel Abbud (ver na figura 8). No qual, sua implantação acarretou em significantes mudanças no espaço urbano.

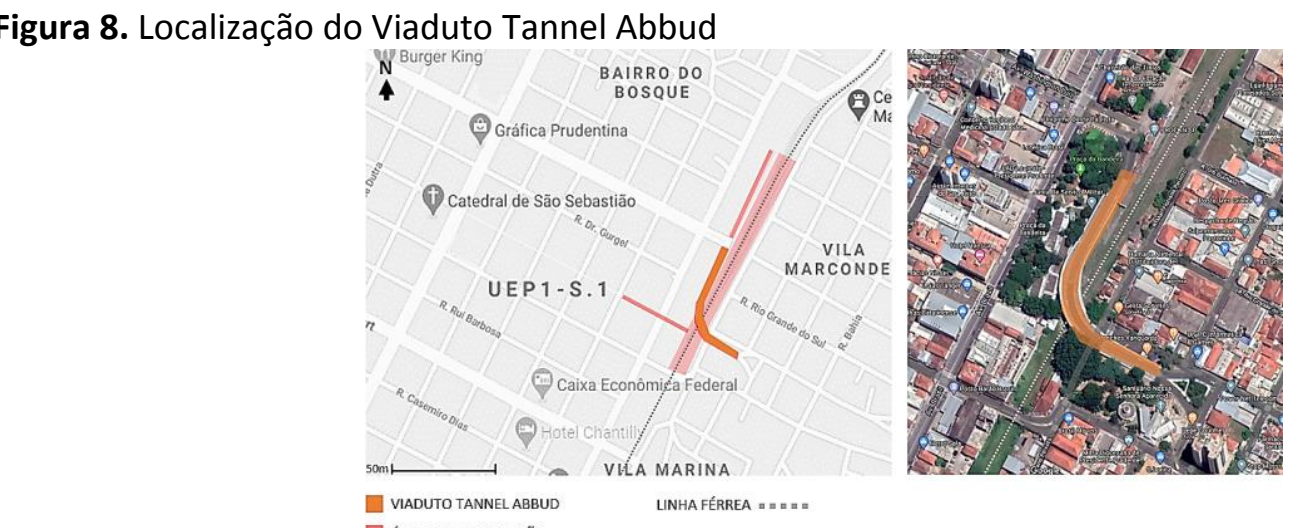




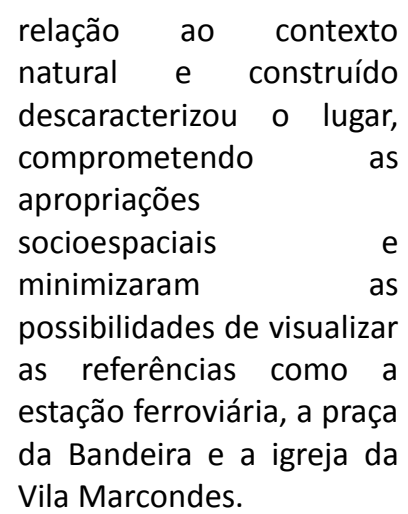

O viaduto sob seu entorno acabou se revelando uma barreira física e visual para as praças ao lado (a Praça da Bandeira e a Nossa Senhora Aparecida), seu entorno imediato, além de alterar seus desenhos iniciais (BISPO, 2011). Onde o viaduto conectava as Vilas Goulart e Marcondes, mas sua implantação interferiu na paisagem histórica original como uma cicatriz urbana.

Acarretando, com o tempo, em mudanças para o seu entorno. Como o fato da Praça da Bandeira ter se tornado um local de apropriação de caráter informal, com comércios e moradores em situação de rua. A alteração no fluxo que havia entre as praças (da Bandeira e Nossa Senhora Aparecida), que diminuiu depois da implantação do viaduto, por conta da dificuldade de acesso entre elas (que agora se dá mais diretamente por um túnel que há na Praça da Bandeira) (HIRAO, 2016).

Outra mudança, foi a transformação do baixio desse viaduto como espaço residual, espaço onde também se encontra a linha férrea, considerado um vazio urbano desde o declínio do transporte ferroviário. Por conta de não apresentar mais uso para a cidade. Logo, o espaço do baixio desse viaduto, com o passar do tempo, por falta de função e identidade se tornou um espaço residual.

Estes espaços considerados residuais urbanos, geralmente são territórios sem uso e abandonados, tanto pela população quanto pelo poder público. Igualmente, esse baixio do viaduto e a linha férrea, espaços sobrantes da implantação de uma infraestrutura e, por isso, lugares ociosos, consequentemente, desestruturados, incómodos, inseguros, rejeitados e à margem de qualquer exploração rentável (PEREIRA, 2011).

Assim, o viaduto Tannel Abbud reflete diretamente o rompimento da malha e o que pode ser considerado um fragmento da cidade. $O$ seu baixio, lugar esse de esquecimento e degradação, se tornou um espaço inativo e marginalizado, consequentemente moradores em situação de rua passaram a ocupar o espaço.

Tal apropriação no espaço urbano acaba revelando como as relações socioeconômicas e culturais interferem na organização social e na vivência do espaço já produzido (PEREIRA, 2011). Distinguir as práticas socioespaciais de ocupação do espaço e os aspectos sociais as quais o mesmo é exposto revela-se de grande relevância dentro do ambiente constituído pela cidade, visto que ele comporta os mais variados tipos de pessoas e consequentemente classes sociais, portanto, necessita de parâmetros e diretrizes urbanísticas para que seus espaços sejam utilizados por todos.

Contudo, para a requalificação dessas áreas residuais e centrais urbanas, há a necessidade de levar em consideração sustentabilidade social e cultural para a cidade, visando as memórias de seu transcurso histórico e as percepções da atmosfera do local (HIRAO, 2016). Para tanto, a importância de intervir, e promover a recuperação desses espaços, considerados fragmentos ou resíduos da cidade, significa melhorar a imagem da cidade e perpetuar a sua história, criar um espírito de comunidade e pertencimento. Significa, também, otimizar o uso e as práticas socioespaciais de ocupação desses espaços a fim de que se tornem espaços públicos, promovendo a reutilização de seu entorno e consequente a valorização.

\section{DISCUSSÃO \\ RELAÇÕES SOCIOESPACIAIS}

$A$ área que se visa a intervenção, já retratada no capítulo anterior, está inserida nos bairros Centro e Vila Marcondes, regiões consideradas antigas, pois deram início ao Município de Presidente Prudente, e uma pequena parcela da área se situa no bairro Vila Jesus, como observado na (Figura 9). Outro bairro adjacente a área de intervenção é o Vila Marina, e ambos os bairros que se encontram no perímetro de análise apresentam características distintas, com diferenças em seus desenhos, topografia, arborização, infraestrutura, entre outros. 
Figura 9. Identificação dos bairros limitantes da área em estudo.

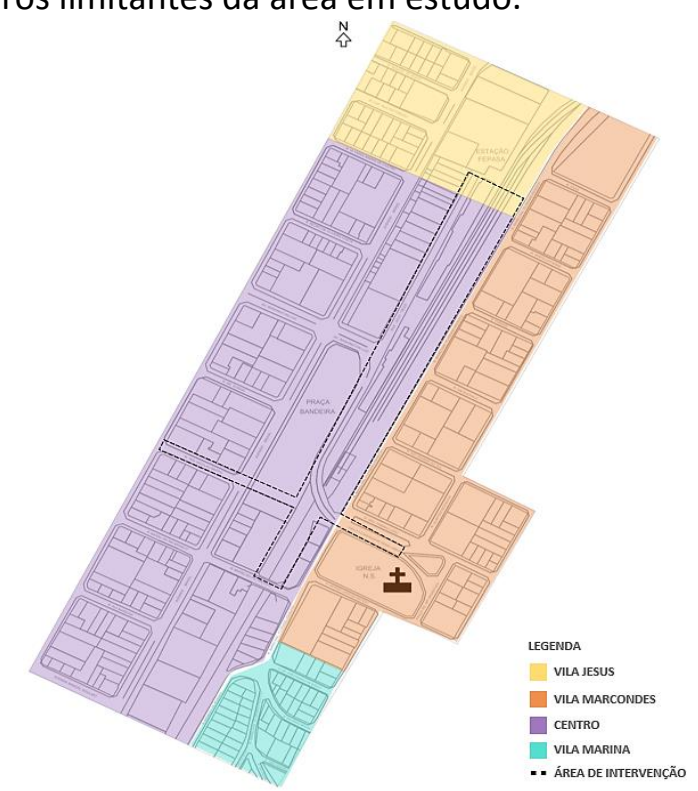

Fonte: Prefeitura Municipal de Presidente Prudente (2020). Editado pela autora.

Segundo o Zoneamento de Uso e Ocupação do Solo (2018) disponibilizado pela Prefeitura de Presidente Prudente (Figura 10), a área proposta para a intervenção, se situa em duas zonas, classificadas como ZE - Zona Especial, especificamente a ZE-11 - Zona Especial de
Transporte Intermunicipal Ferroviário (área de linha férrea) e ZCS1 - Zona de Comércio e serviço central, de ocupação vertical, o que equivale a uma zona especial e comercial.

Figura 10. Zoneamento de Uso e Ocupação do Solo da área.

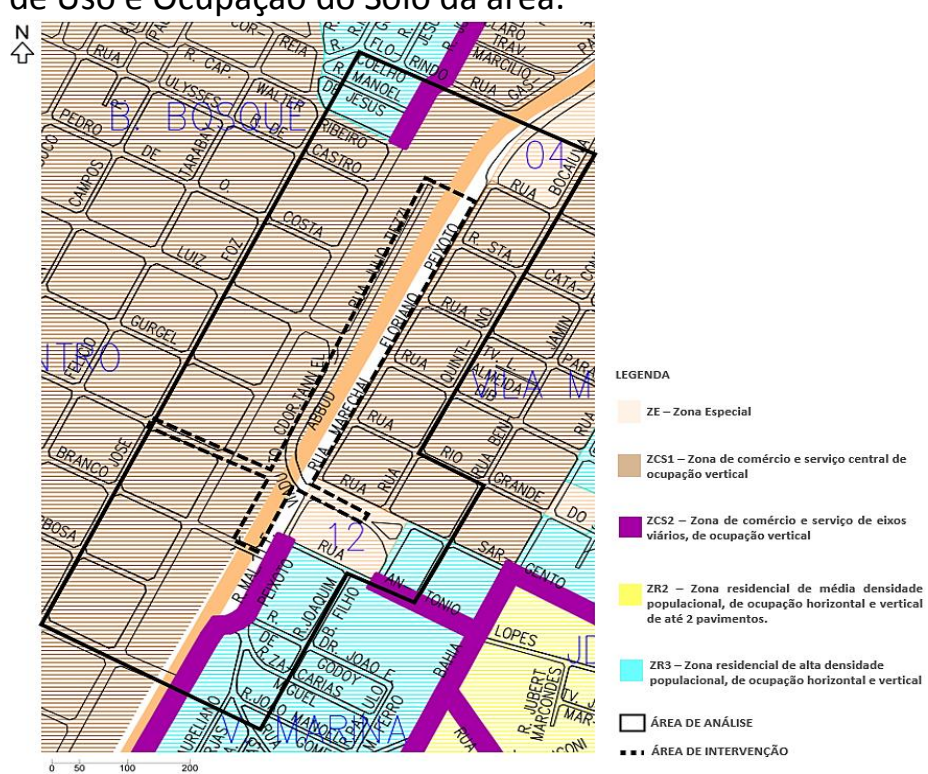

Fonte: Prefeitura Municipal de Presidente Prudente (2020). Editado pela autora.

Assim, podemos notar que a área em estudo, se encontra próxima a estação ferroviária, sendo uma região de predominância comercial e residencial, conforme visualizamos na figura 11. Desse modo, de acordo com levantamentos in loco, pode-se perceber que nos horários e dias comerciais, a área é uma região bastante movimentada, principalmente nos horários de pico ( $8 \mathrm{~h}, 12 \mathrm{~h}$ e $18 \mathrm{~h}$ ). 
Figura 11. Uso e Ocupação do Solo da área em estudo.

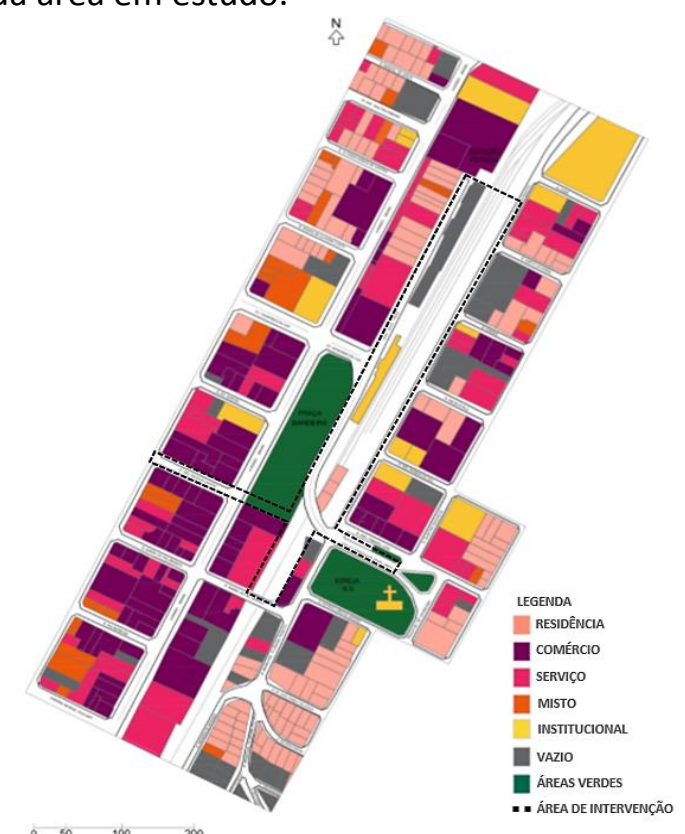

Fonte: Prefeitura Municipal de Presidente Prudente (2020). Editado pela autora.

Entretanto, no período noturno, é notável a falta de movimento. O fluxo de carros se mantém apenas na Avenida Brasil (até às 22h). Assim, toda a área que antes estava ocupada por pessoas exercendo suas atividades, agora é praticamente ociosa. Em alguns pontos também se nota a presença de moradores de rua e prostitutas, principalmente no período noturno.

Outro aspecto avaliado a partir de análises das áreas ocupadas do perímetro em estudo foi levantado no mapa de figuro e fundo (figura 12), onde podemos visualizar a relação dos vazios urbanos, das ruas e das áreas ocupadas. É possível identificar uma grande parcela não ocupada por edificações, ao passo que, o crescimento acelerado da cidade de Presidente Prudente ocasionou na presença de diversos vazios urbanos no centro da cidade.

Figura 12. Figura e Fundo da área em estudo.

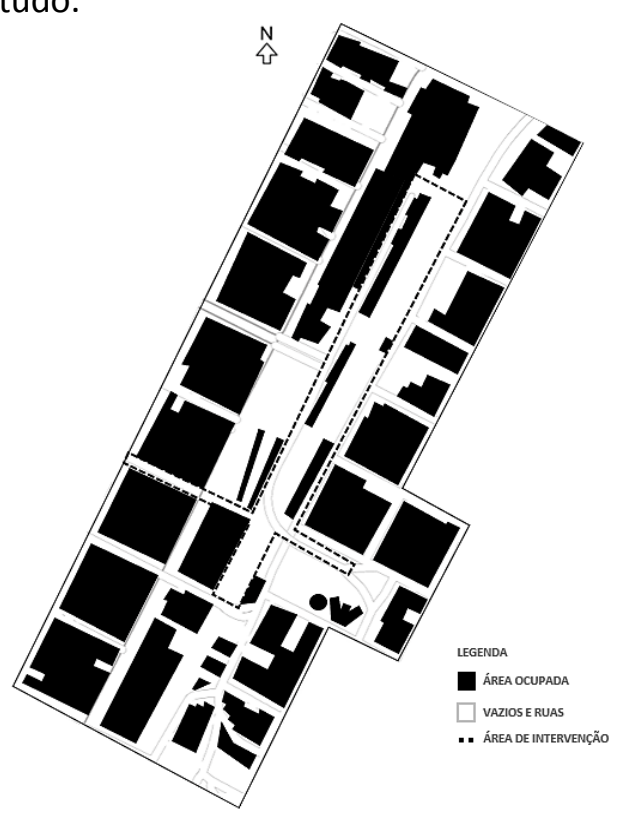

Fonte: Prefeitura Municipal de Presidente Prudente (2020). Editado pela autora. 
Também se destacam as áreas ocupadas dentro dos limites do espaço de intervenção de projeto, evidenciando desse modo os lotes que permeiam a linha ferroviária (como os galpões e casas adjacentes) ou que se encontram ao derredor da área de intervenção, os quais delimitam a região em estudo. E podemos observar que as áreas que possuem maior parcela de vazios são os bairros Vila Marcondes e Vila Marina, regiões que possuem traçados urbanos mais irregulares, marcados por usos mais residenciais.
Cruzando os aspectos analisados e já
citados anteriormente, delineamos características do traçado urbano da área em estudo, que foram observados e estabelecidos seguindo os conceitos de morfologia urbana definidos por Mascaró, os quais podemos visualizar esta identificação das malhas urbanas no mapa da figura 13, que cuja descrição pontuada é especificada logo em seguida.

Figura 13. Identificação da malha urbana da área em estudo.

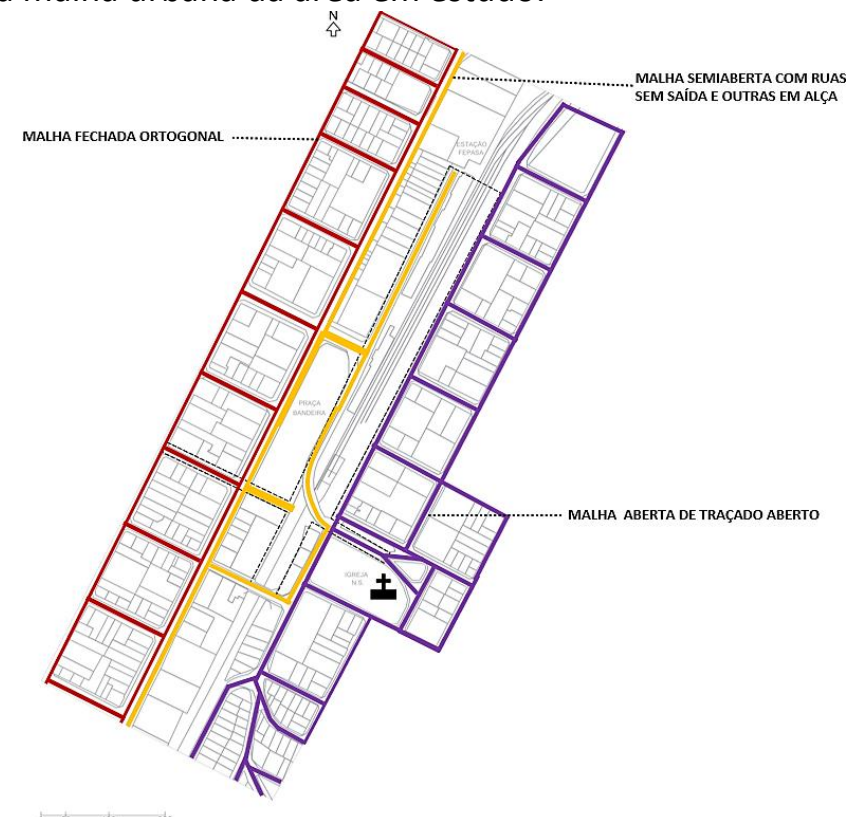

Fonte: Prefeitura Municipal de Presidente Prudente (2020). Editado pela autora.

A malha urbana fechada que está presente na área, é uma malha que se subdividese em malha ortogonal, malha não ortogonal e malha triangular (FARIAS apud MASCARÓ, 2013). E esta malha ortogonal se encontra majoritariamente no Centro e em uma parcela da Vila Jesus, um traçado urbano mais regular. $E$ segundo Mascaró (FARIAS apud MASCARÓ, 2013), estes traçados ortogonais trazem mais benefícios, uma vez que o traçado regular faz com que haja melhor aproveitamento do quarteirão, além de ter menores custos com sinalização em cruzamentos perigosos.

Já os outros bairros da área em estudo possuem outras malhas, malha aberta na Vila Marcondes e em uma parte da Vila Marina, e semiaberta em uma parcela do Centro. Estas malhas, aberta e semiaberta são subdivididas em malha espinha de peixe, malha em $\mathrm{T}$, malha aberta e de traçado aberto e malha semiaberta com ruas sem saída e outras em alça. E tais malhas tem como característica mais áreas de lotes do que de sistemas viários (FARIAS apud MASCARÓ, 2013).

Desse modo, como já vimos anteriormente a área do Centro é a mais valorizada, e concentra mais infraestrutura do que as outras do perímetro em estudo, na figura 14 esse aspecto é evidenciado com a sobreposição de todas as análises de infraestrutura urbana. Na Vila Marcondes, na área próxima à Igreja Nossa Senhora Aparecida e do Centro Cultural Matarazzo também há uma boa quantidade de infraestruturas. 
Figura 14. Infraestrutura urbana da área em estudo

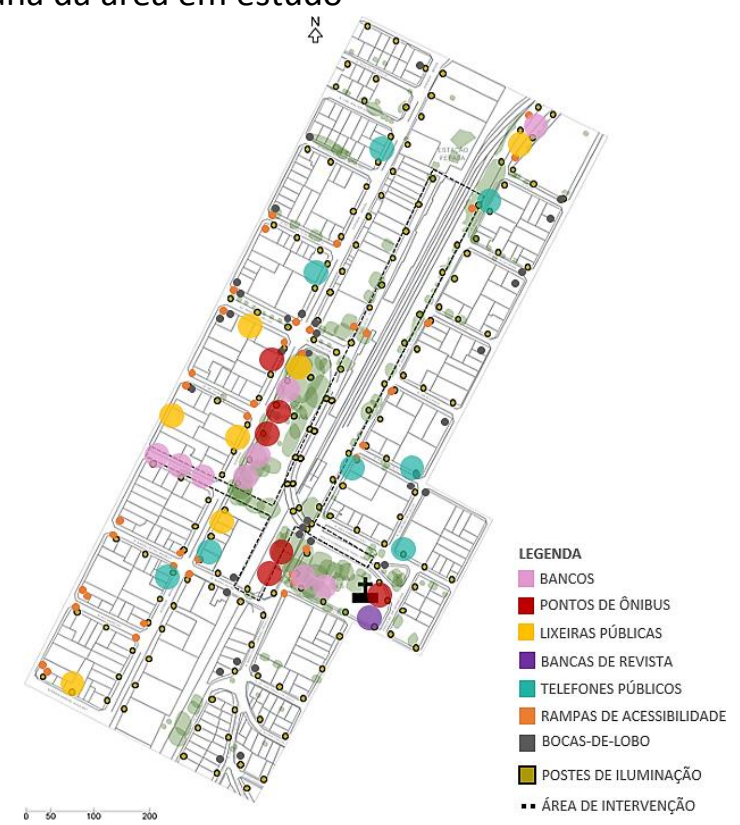

Fonte: Prefeitura Municipal de Presidente Prudente (2020). Editado pela autora.

Com tais características conseguimos indicar que a maior concentração de infraestruturas está em uma parte do Centro e em uma da Vila Marcondes, áreas mais desenvolvidas que possuem mais investimentos. Já nas outras áreas, de caráter mais residencial detêm de uma precariedade no espaço urbano, junto a sua infraestrutura, como seus mobiliários e qualidade do espaço.

É assim uma das principais características definidoras do espaço urbano. Pois, determinadas áreas podem ser valorizadas se houver interesse do capital, instalando melhorias, ou seja, a transformação das áreas no interior da cidade depende dos inúmeros interesses que permeiam a produção e reprodução do espaço urbano, ao longo dos anos. Assim, por ser uma área no centro da cidade há potencialidades em relação aos seus fluxos e atividades, o que possibilita a qualidade e o bem estar dos moradores da área e facilita o percurso das pessoas (FARIAS apud MASCARÓ, 2013).

Portanto, o centro tem um papel essencial no transporte de mercadorias e pessoas, no qual o quanto mais intensos os fluxos que convergem/divergem a partir de um centro, maior o estímulo para investimentos nesse centro, o que por sua vez, reforça a sua centralidade (FARIAS apud MASCARÓ, 2013).

\section{INTERVENÇÃO EFÊMERA COMO FERRAMENTA PARA REPENSAR O ESPAÇO URBANO}

Ao analisar a área de estudo vê-se como objetivo promover uma intervenção de caráter efêmera, se constituindo em algo temporário no lugar de intervenção, a fim de servir como ferramenta de transformação de espaços residuais públicos já existentes no centro da cidade de Presidente Prudente - SP, proporcionando a amabilidade urbana.

A amabilidade trata-se de um atributo espacial que se manifesta através de conexões e interações entre pessoas e espaço, opondo-se ao individualismo que por muitas vezes caracteriza as formas de convívio coletivo contemporâneo. Portanto, a amabilidade, é uma qualidade física e social ao mesmo tempo: poderia considerá-la como resultado da soma do contexto físico (espaço potencialmente atraente) com o contexto social (pessoas), que se unem através da presença da intervenção temporária (FONTES, 2013). Desse modo, será utilizado como proposta de projeto uma intervenção que não interfere no espaço, a condição da efemeridade, como ferramenta de experimentação e discussão.

Esta forma de intervenção permite pôr em prática (de forma rápida e temporária) desafios urbanos novos ou polêmicos, como a convite de uso das ruas para pessoas, usos em baixios de viadutos ou outros vazios urbanos (FONTES, 2013). Também permite-nos 
reinterpretar espaços da cidade e sua apropriação pelas pessoas.

As intervenções temporárias são transformações do espaço provenientes de uma forma contemporânea de pensar e agir, que apesar de temporárias, podem causam impactos permanentes sobre os lugares, interferindo nos espaços da vida coletiva e estimulando a amabilidade urbana, alguns exemplos destas intervenções podemos ver na figura 15. Onde essa intervenção permite a ativação de espaços obsoletos por meio de novas conexões entre pessoas (FONTES, 2013). Assim ampliando o espaço público e valorizando o uso coletivo.

Figura 15. Intervenções efêmeras como estímulo da vida coletiva

Fonte: ArchDaily (2018).

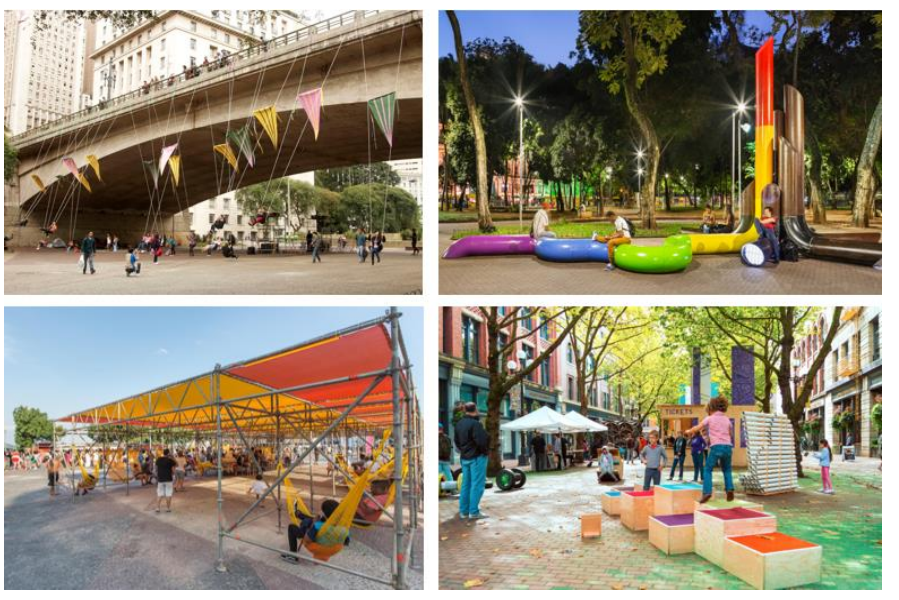

Logo, as intervenções temporárias são como as ações que se movem no campo do transitório, do pequeno, das relações sociais, que envolvem a participação, ação, interação e subversão, e que são motivadas por situações existentes e particulares do contexto urbano, em contraposição ao projeto convencional, caro, permanente e de grande escala. Ao passo que estas intervenções, diferentemente dos usos na cidade são ações que tem o objetivo de transformação do espaço, funcionando como estímulo de relações e de proximidade, tanto com o próprio espaço, quanto em relações entre os indivíduos (FONTES, 2013).

Concluindo, pautados nesses preceitos, a proposta visa enaltecer a cidade, sua história e a escala do pedestre, trazer e incentivar os usos dos espaços públicos. A mesma junto aos levantamentos urbanos e sua condição efêmera busca trazer a aproximação das pessoas com os espaços públicos, somada a realidade existente do lugar, se baseando da apropriação e espontaneidade das atividades do lugar.

Desse modo, a mesma se pauta em incentivar a identidade local e as manifestações e usos que ocorrem na área, como utilização de espaços públicos ou vazios urbanos pelos moradores e coletivos, como o Galpão da Lua; transposições nos locais de intervenção e caminhos de desejo dos pedestres (caminhos não definidos, mas marcados pela passagem constante de pedestres) e percursos realizados por ciclistas e pedestres na linha férrea e no viaduto Tannel Abbud. Podemos visualizar estas considerações pontuadas no mapa síntese (figura 16), como sendo as considerações principais do local de estudo para estabelecer as propostas. 
Figura 16. Mapa síntese das principais considerações do local.

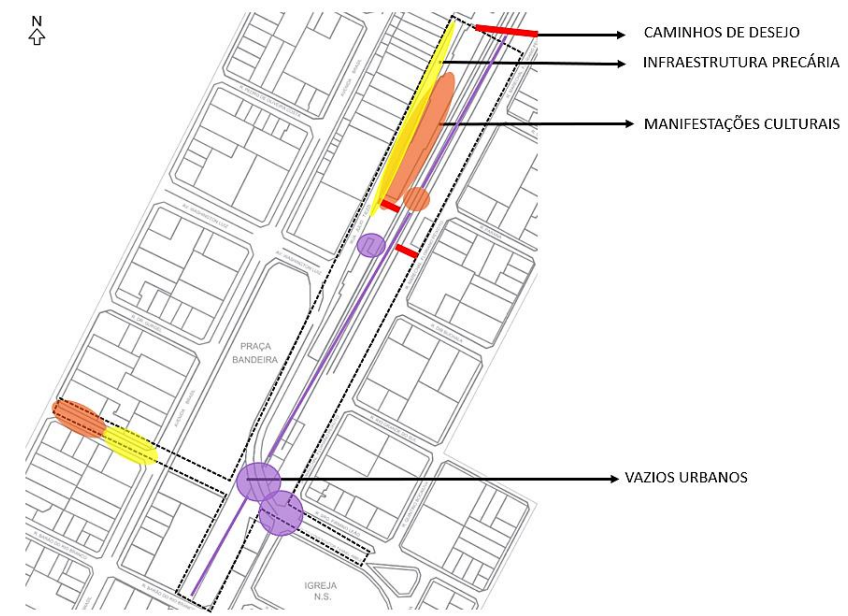

Fonte: Prefeitura Municipal de Presidente Prudente (2020). Editado pela autora. Sem escala.

Assim, o projeto propõe diretrizes e intervenções itinerantes em espaços pontuais, a fim de as pessoas verem a cidade e a repensarem. Desse modo, a primeira definição da proposta é compreender as dinâmicas da área, o que possibilitou identificar a diversidade de usos que ela apresentou ao longo de sua história, seja aqueles ligados ao comércio itinerante, feiras, eventos - escolares, culturais, musicais, teatros e apresentações diversas.

A área demonstra uma ampla gama de usos, não premeditadamente definidos, como manifestações da vida que se encenam e se modificam dia a dia (caráter efêmero da cidade contemporânea). Sendo esse outro atributo que define o partido, a multifuncionalidade regida pela imprevisibilidade da vida. Outros aspectos que foram relevantes para estabelecer as diretrizes do projeto foram os levantamentos urbanos da área, e estas características estão sintetizadas na figura 17 , a seguir.

Figura 17. Quadro síntese dos levantamentos da área em estudo

\begin{tabular}{|l|l|}
\hline \multicolumn{2}{|c|}{ SÍNTESE DOS LEVANTAMENTOS DA ÁREA EM ESTUDO } \\
\hline \multicolumn{1}{|c|}{ POTENCIAIS } & \multicolumn{1}{c|}{ PROBLEMÁTICAS } \\
\hline CENTRALIDADE - TEM MAIOR INVESTIMENTO & CENTRALIDADE (ESPECULAÇÃO IMOBILIÁRIA E GENTRIFICAÇÄO) \\
\hline USO MISTO - COMERCIALIRESIDENCIAL & PERFIL SOCIOECONÔMICO (CONTRASTE) - CLASSE MÉDIA/BAIXA \\
\hline VÁRIOS EQUIPAMENTOS URBANOS & FAIXA ETÁRIA CONTRASTANTE - IDOSOS/JOVENS \\
\hline ÁREA DE FORTE PRESENÇA CULTURAL & DESCONEXÄO DE ÁREAS E DIVERSOS VAZIOS URBANOS \\
\hline ÁREA HISTÓRICA DA CIDADE - AFETIVO & POUCA ARBORIZAÇÄO NA LINHA FÉRREA - INSOLAÇÃO \\
\hline ARQUITETURA ART DECO - EDIFICIOS & MORADORES DE RUA, USUÁRIOS DE DROGAS E ÁREAS OCIOSAS \\
\hline ALTO FLUXXO NO PERIODO COMERCIAL & ALTO FLUXO - PERIODO COMERCIAL, A NOITE VAZIO \\
\hline VIAS DE FLUXO RÁPIDO E UMA MAIS TRANQUILA & POUCA ILUMINAÇÃO - SENSAÇÃO DE INSEGURANÇA \\
\hline RUAS E CALÇADAS DE QUALIDADE - CENTRO & ÁREAS DE LAZER QUE NÃO SÃO FREQUENTADAS \\
\hline SINALIZAÇÕO ADEQUADA EM SUA MAIORIA & POUCO MOBILIÁRIO URBANO NA MAIOR PARTE DA ÁREA \\
\hline DIVERSIDADE DE MANIFESTAÇÕES COLETIVAS & FALTA DE ACESSIBILIDADE \\
\hline DIVERSIDADE DE ATIVIDADES & VIAS DE FLUXO RÁPIDO, MOVIMENTO INTENSO - RUIDOS \\
\hline GRANDE PRESENÇA DE PEDESTRES E CICLISTAS & ÁREAS DE CONFLITO DE CARROS E PEDESTRES \\
\hline DUAS PRAÇAS, E BEM ARBORIZADAS & VÁRIOS ENTULHOS NAS LOCALIDADES \\
\hline
\end{tabular}

Fonte: Autora 2020.

Diante do que já foi dito anteriormente, a proposta de intervenção urbana de caráter itinerante como podemos ver é definida como itinerante, instante, espontânea e que incentiva manifestações, assim a proposta de projeto traz o conceito de re/ver a cidade de forma itinerante, a fim de trazer o envolvimento civil para repensar e melhorar o espaço urbano. 
O projeto traz a os espaços públicos como palco onde as diversas formas de manifestações da vida acontecem, se materializam, desse modo é necessário oferecer um meio para não só abrigá-las, mas incentivá-las para que ocorram. Assim, para incentivar essa identidade local, como esses usos e manifestações espontâneas (ver na figura 18) que são existentes na área, o projeto traz diretrizes que serão pautadas em termos como intervenções de valor efêmero, caráter temporário, apropriações e usos locais, conexões e espaços coletivos.

Figura 18. Identidade local.
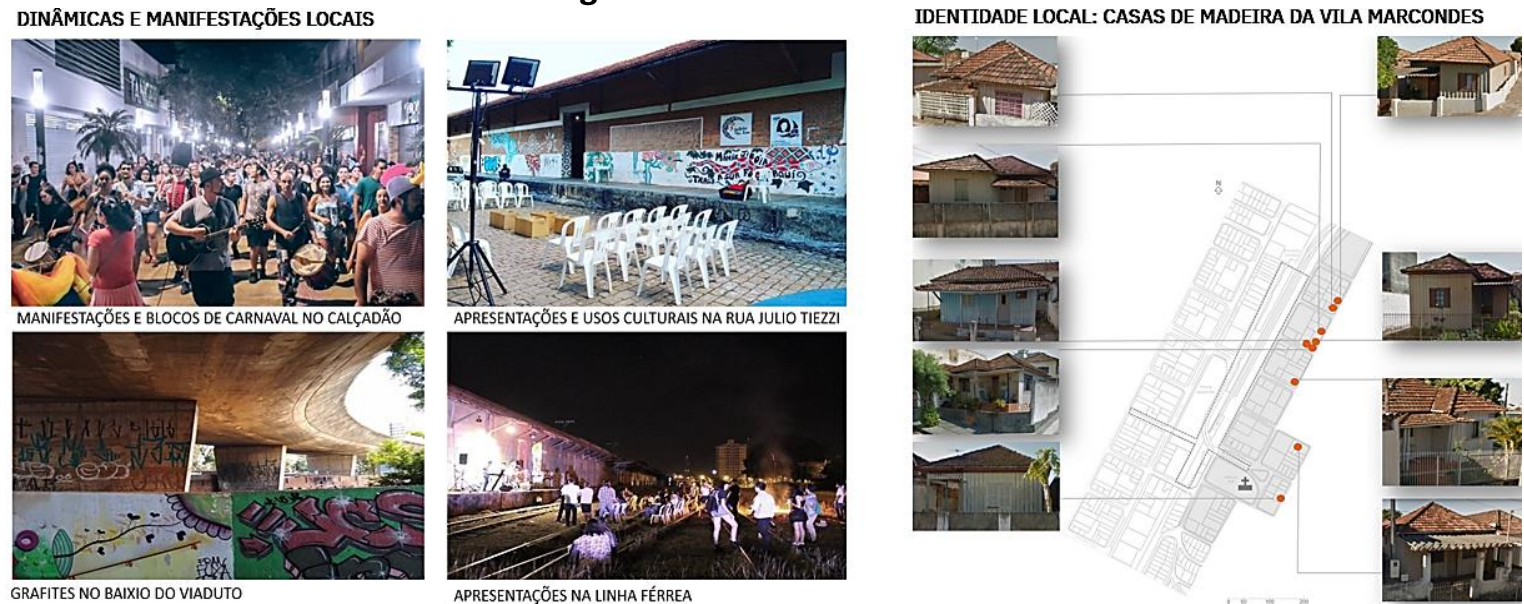

Fonte: Prefeitura Municipal de Presidente Prudente (2020). Editado pela autora.

Para concretizar o conceito do projeto, faz-se como partido o desenvolvimento de um circuito itinerante, com o objetivo de trazer intervenções efêmeras pontuais que se conectam, sejam por cores, por materialidade ou proximidade. Estas intervenções que fazem parte desse circuito foram denominadas por eventos, para desenvolver melhor uma setorização e separar elas por similaridades relacionadas com as características locais em que se inserem. Esses eventos são (ver na figura 19):

- Ruas abertas - Trazer diretrizes e intervenções pontuais em ruas abertas (Calçadão) ou propor diretriz de transformação como uma rua multimodal (rua Julio Tiezzi). Utilizando-se de mobiliários e pinturas removíveis.

- Museu do Instante - Também com intervenções pontuais, a fim de transformar o baixio do Viaduto Tannel Abbud em um museu urbano passageiro, e transformar túnel em galeria de grafite (incentivando o uso já existente de ambos os locais). Fazendo uso de mobiliários e estruturas modulares como apoio e pinturas removíveis.

- Percurso cidade em movimento - Diretrizes e intervenções pontuais na linha férrea, induzindo um percurso para permitir o pedestre a caminhar pela cidade em uma passarela itinerante. 
Figura 19. Setorização e planta esquemática
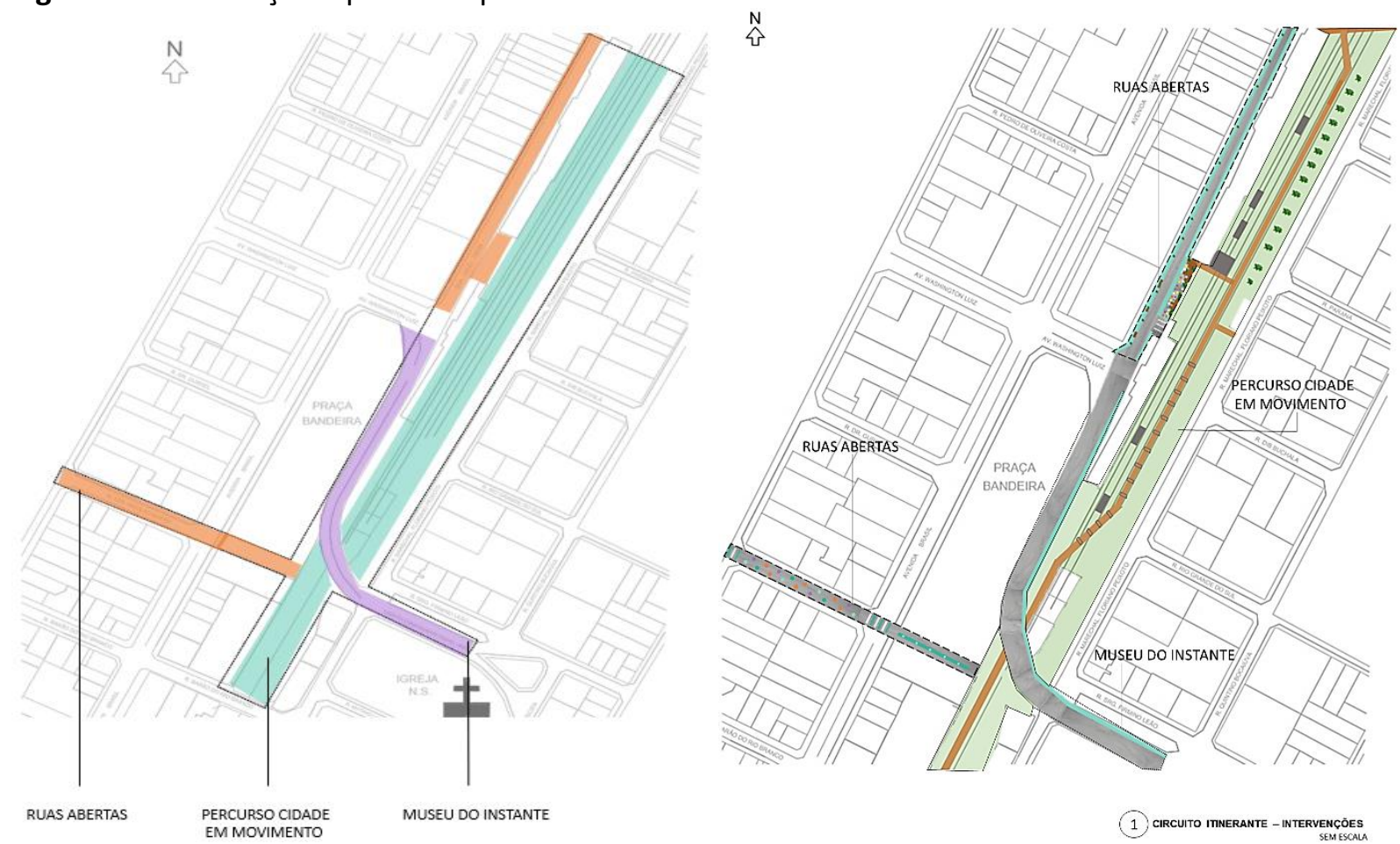

Fonte: Prefeitura Municipal de Presidente Prudente (2020). Editado pela autora. Sem escala.

Levando em consideração a dimensão da área, é compreendido que há necessidade de trazer diretrizes para melhoria local em conjunto a proposta já citada anteriormente. Tais diretrizes visam trazer benefícios para os bairros locais, melhorando infraestrutura, iluminação e segurança, gerando apoio as atividades e manifestações culturais locais existentes, e melhorando fluxo de pedestres e veículos. Reduzindo então áreas ociosas e sem uso. Desse modo, estas diretrizes se apresentam listadas a seguir:

- Parceria público e privado programa ambiental junto à comunidade: coleta seletiva, projeto de compostagem, horta comunitária (trazer alimento para comunidade carente) e plantio de árvores.

- Parceria público e privado programa social: propostas com universidades, escolas e voluntários de para proporcionar oficinas colaborativas e percursos urbanos que mostram a cidade e sua história; trazer eventos culturais locais (feiras da comunidade e incentivo de manifestações existentes); programa social de auxílio e apoio a moradores de rua; oficinas colaborativas de construção de mobiliários urbanos.

- Desenho de faixa de ciclovia e ciclofaixa na superfície do viaduto e na rua Julio Tiezzi, e desenho e placas de sinalização (para evitar os conflitos existentes entre pedestres e automóveis nos locais ao redor).

- Parceria público e privado: melhoria na infraestrutura urbana local.

- Parceria público e privado: modificação de rua comum (rua Julio Tiezzi) para rua multimodal.

- Intervenções efêmeras: projetos que incentivam manifestações culturais e não interferem na paisagem; materialidade de projeto que contrasta com paisagem e valorizando edifícios antigos e patrimoniais ao derredor. 
Ressalta-se, ainda, que estas diretrizes objetivam o impacto positivo principal em questão, de reduzir os vazios urbanos existentes nos bairros que configuram a área de intervenção, assim gerando adensamento benéfico na área urbana com infraestrutura, adjunto a melhoria da qualidade de vida no espaço público.

\section{CONCLUSÃO}

A área de intervenção apresentada neste trabalho e alvo do estudo de diretrizes projetuais se localiza no centro da cidade de Presidente Prudente, munícipio que se início com duas áreas desenvolvidas a partir da Estrada de Ferro Sorocabana, passou por uma acelerada expansão urbana, a qual depois se configurou com um espaço urbano com necessidade por espaços públicos de qualidade e com surgimento de espaço residuais.

Os quais são descritos como intersticiais, sobras da urbanização sem planejamento. Alguns desses exemplos de resíduos urbanos do centro da cidade, forte identidade da mesma são o Viaduto Tannel Abbud e a linha férrea, que está inserida em seu baixio. A construção deste viaduto Comendador Tannel Abbud na área central da cidade acarretou na descaracterização do entorno onde foi implantado e diminuiu o uso do local, ao lado da estação ferroviária, sua área inferior, chamada de baixio.

Desse modo, esta área retratada pela literatura acadêmica como espaço residual, compreende-se por ser ocioso e desvalorizado, com conflitos de uso entre comércio informal e moradores de rua. Para tanto, ao investigar o histórico e dinâmicas desse espaço foram propostos direcionamentos e intervenção de caráter efêmera, a fim de gerar a amabilidade urbana.

Evidenciando que com os estudos a proposta de intervenção urbana de caráter itinerante seria de melhor escolha para tal área, ao ser uma alternativa que auxilia no desafio de ativar áreas residuais e de ser uma intervenção reversível e modular. Na qual busca incentivar as manifestações e usos existentes no local.

No entanto, a proposta busca discutir os espaços públicos e residuais do centro da cidade, utilizando de uma intervenção itinerante para conceber ao usuário a possibilidade de um percurso urbano que o faça re/ver a cidade, trazendo assim o envolvimento civil para repensar e melhorar o espaço urbano.

\section{REFERÊNCIAS}

AGOSTINHO, M. V. V. Reabilitação da área central de Presidente Prudente: interligando a Praça da Bandeira ao seu entorno. 2009. $92 \mathrm{f}$. Trabalho de Conclusão de Curso (Graduação em Arquitetura e Urbanismo) - Faculdade de Ciências e Tecnologia, Universidade Estadual Paulista, Presidente Prudente, 2009.

BELTRÃO SPOSITO, Maria E. O chão em Presidente Prudente: a lógica da expansão territorial urbana. Rio Claro: IGCE, Dissertação (Mestrado em Geografia) 1983.

BISPO, T. M. S. As Praças Centrais de Presidente Prudente-SP: avaliação do caráter como subsídio para intervenções projetuais. 2011. 119 f. Trabalho de Conclusão de Curso (Graduação em Arquitetura e Urbanismo) - Faculdade de Ciências e Tecnologia, Universidade Estadual Paulista, Presidente Prudente, 2011.

FONTES, A. S. Intervenções temporárias, marcas permanentes: apropriações, arte e festa na cidade contemporânea. Rio de Janeiro. Casa da Palavra: Faperj, $2013 . \quad$ DOI: https://doi.org/10.4013/arq.2012.81.05

FURTADO, G. S. Ativação urbana em espaços residuais. 2016. Trabalho de Conclusão de Curso (Graduação em Arquitetura e Urbanismo) Centro Universitário Moura Lacerda, Ribeirão Preto, 2016.

GUATELLI, I. Arquitetura dos Entre-lugares: Sobre a importância do trabalho conceitual. São Paulo: Senac, 2012.

HIRAO, H. Paisagem Histórica de Presidente Prudente (Vila Goulart e Vila Marcondes): cenário e atmosfera na cidade atual. In: COLÓQUIO IBERO-AMERICANO PAISAGEM CULTURAL PATRIMÔNIO E PROJETO, 4., 2016, Belo Horizonte. Anais [...]. Belo Horizonte: UFMG, 2016, p.1-15.

IBGE. Instituto Brasileiro de Geografia e Estatística. Presidente Prudente. 2019. Disponível em:

https://cidades.ibge.gov.br/brasil/sp/presidenteprudente/panorama. Acesso em: 20 de mar 2020.

LYNCH, K. A imagem da cidade. 2. ed. São Paulo: 
Martins Fontes, 2010.

MASCARÓ, J.L. Manual de loteamentos e urbanizações. Porto Alegre: SAGRA-DCLuzzato, 1994.

PEREIRA, J. I. C. Espaços residuais urbanos: Os 'baixios' de viadutos. 2011. Dissertação (Mestrado Integrado em Arquitetura e Urbanismo) - Faculdade de Ciências e Tecnologia, Universidade de Coimbra, Coimbra, 2011.

PREFEITURA DE PRESIDENTE PRUDENTE. Governo de Presidente Prudente. A cidade: História e informações, conheça Presidente Prudente. 2017. Disponível em: http://www.presidenteprudente.sp.gov.br/site/ac idade.xhtml. Acesso em: 19 de mar. 2020.

SOLÀ-MORALES, Ignasi, "Territórios", 2002, Editorial Gustavo Gili SA, Barcelona.

WHITACKER, A.M. A produção do espaço urbano em Presidente Prudente: uma discussão sobre a centralidade urbana. Dissertação (Mestrado em Geografia). Presidente Prudente: Faculdade de Ciências e Tecnologia da UNESP, 1997. 